\title{
Role stress among doctors working in a Teaching Hospital in Sri Lanka
}

\author{
Gunawardane DA ${ }^{1}$, Mallawaarachchi $\mathrm{SI}^{2}$, Herath $\mathrm{PHM}^{3}$, Anwarama $\mathrm{RS}^{3}$, Warnasuriya WPGS 3
}

\begin{abstract}
Background: Role (Work) stress impact not only on doctor's health but also their ability to cope with their job demands or patient care. Organizational Role Stress (ORS), is the stress explained by the persons because of their role (job) in the organization. It has 10 dimension scores.

Objectives: The aim of this study was to describe the level organizational role stress, its associated factors and underline role stressors among all non-specialistmedical officers working in the Teaching Hospital Peradeniya (THP).

Methods: This is a descriptive cross-sectional study. The data was collected by using self-administered questionnaire, which includes Organizational Role Stress (ORS) Scale.All non-specialist medical officers $(n=138)$ working in THP were considered as potential study participants.

Results: The study includes 76 respondents (out of 138 doctors) from the different wards and units at THP. The majority were male ( $n-41,53.9 \%$ ) and married ( $n-59,77.6 \%)$. Mean ORS score was 65.5 (SD-32.04). The majority ( $n-39,51.3 \%$ ) of the doctors were having low-medium role stress (ORS score $51-100$ ) and $35.5 \%$ had low role stress (ORS score $0-50)$. But $11.8 \%(n-9)$ and $1.3 \%(n-1)$ had high medium role stress (ORS score 101-150) and very high role stress level (ORS score 151-200). ORS levels were found to have, statistically significant relationships with marital statuses, age, years of experience and management level but not with the sex.

Conclusions: Findings of this study revealed that doctors working at THP were suffering from medium to high levels of ORS and Inter Role Distance (IRD), Role Stagnation (RS), Role Overload (RO) and Personal Inadequacy (PI) were reported as the major role related problems among them. Role Ambiguity (RA) is found to be the least problematic role stressor among doctors. The finding of this study demands the attention of administrators and policymakers, to provide an attractive working climate in order to decrease the side effects and consequences of role stress and increase the productivity of the doctors.
\end{abstract}

Keywords: Role stress, Doctors, Teaching Hospital, Sri Lanka

\section{Introduction}

Every profession is not equally stressful. It depends on the hierarchy of the position and scope of competencies and responsibilities. Organizational stress or work stress is a long-standing concern of the healthcare organizations. ${ }^{1}$

Despite the debate among researchers how to define the stress, Selye's ${ }^{2}$ definitionis commonly used in the literature. He defines stress as a non-specific

1. Consultant Community Physician, Regional Director of Health Services Office, Nuwaraeliya.

2. Senior Registrar in Psychiatry,Teaching Hospital, Peradeniya, Sri Lanka.

3. Medical Officer,Teaching Hospital Peradeniya. RILanka

\section{Corresponding author}

Damitha Asanga Gunawardane

E mail - damithagunawardane@gmail.com iD https://orcid.org/0000-0001-8844-296X response of the body to any demand made upon it. The interaction model of stress proposed by the Moore et.al. ${ }^{3}$ includes three big factors; work, home and personality.

As defined by Khan and others", "role" is a set of functions, which is an individual performs in response to the expectations of others as well as his own expectations.So the stress due to person's role in the organization is termed as organizational role stress. ${ }^{5}$ In this study, investigators have specifically focused the term "organizational role stress" because it is well-defined than the work stress.Pareek5identified ten different types of organizational stressors. Those were briefly described in Table -01 .

There were very few published research works in Sri Lanka regarding work stress ${ }^{6}$ including one study on psychological distress and coping strategies among female student nurses. ${ }^{7}$ However,as far as we know there has not been any published research work on doctor's role (work) stress in Sri Lanka. 
Table 1-Types of Organizational Role Stress

\begin{tabular}{|c|c|}
\hline Inter-Role Distance (IRD) & $\begin{array}{l}\text { Which is experienced when there is a conflict between } \\
\text { Organizational and non-organizational roles. }\end{array}$ \\
\hline Role Stagnation (RS) & $\begin{array}{l}\text { The feeling of being stuck in the same role for long due } \\
\text { to lack of opportunities or development. }\end{array}$ \\
\hline $\begin{array}{l}\text { Role Expectation } \\
\text { Conflict (REC) }\end{array}$ & $\begin{array}{l}\text { Conflicting demands originating from superiors, } \\
\text { subordinates or peers. }\end{array}$ \\
\hline Role Erosion (RE) & $\begin{array}{l}\text { When a role occupant feels that others are performing } \\
\text { certain functions, which should have been a part of his role. }\end{array}$ \\
\hline Role Overload (RO) & Which is the feeling that one is required to do too much. \\
\hline Role Isolation (RI) & $\begin{array}{l}\text { A person feels that his role is isolated from the } \\
\text { mainstream of organizational life. }\end{array}$ \\
\hline Personal Inadequacy (PI) & $\begin{array}{l}\text { Which will create by the lack of adequate skills and the } \\
\text { resulting inability to meet the demands of one's role. }\end{array}$ \\
\hline Self-Role Distance (SRD) & $\begin{array}{l}\text { Which arises from a gap between one's concept of self and } \\
\text { the demands of his role. }\end{array}$ \\
\hline Role Ambiguity (RA) & Due to lack of clarity about the demands of the role \\
\hline Resource Inadequacy (RIN) & $\begin{array}{l}\text { Which arises when human and material resources allocated } \\
\text { are inadequate to meet the demands of the role. }\end{array}$ \\
\hline
\end{tabular}

Even though, work stress is a major contributing factor to growing job dissatisfaction among doctors, very few studies have been conducted on the occupational stress of doctors in developing countries compared to the developed countries.A descriptive cross-sectionalstudy, ${ }^{9}$ conductedamong a group of doctors $(n=73)$ in a government hospital by using ORS Scale, found that doctors are serious sufferers of organizational role stress. Another study conductedbyDasgupta and $\operatorname{Kumar}^{10}$ using the ORS Scale reported Role overload(RO) as the most significant factor causing role stress among doctors working in Shimla( $n=150)$.

As reported by 11the doctors and other health professionals showing ahigher level of stress (28\%), compared to the general working population(18\%). Most importantly, stress in the medical professionals has potentially serious consequences not only to the medical practitioner but also to the commu- nity. In other words, the "stress and strain in medical professionals are likely to affect their work performance, including the quality of patient consultations and prescribing, as well as adversely affect their own personal and family life". ${ }^{12}$

As further described by Dasgupta, Kumar 10 "Workrelated stress has been implicated as a major contributing factor to growing job dissatisfaction among doctors. It has been found that job stress impacts not only on doctor's health but also their abilities to cope with job demands. This will seriously impair the provision of quality care and the efficacy of the health service delivery".

So it is important to identify such stress among medical practitioners. Therefore the aim of this study was to describe the level organizational role stress, its associated factors and underline role stressors among non-specialist medical officers working at Teaching Hospital Peradeniya (THP). 


\section{Materials and Methods}

This is a descriptive cross-sectional study, which was conducted at Teaching Hospital Peradeniya (THP) during the period from January 2014 to March 2014. The data were collected from non-specialist medical officers working at THP by using a self-administered standardized questionnaire, which includes Organizational Role Stress (ORS) Scale. Questionnaires were distributed to all the non-specialist medical officers in an envelope and asked them to put it into box kept at the medical officer's restroom, after they fill it. The ORS scale is a tool developed and standardized by Pareek et.al. ${ }^{5}$ to measure the role stress. Organizational Role Stress (ORS) scale comprises 50 items. This tool was reported to have anacceptable level of retest reliability $(0.73)^{13}$ and construct validity. ${ }^{14}$ The respondents rate each item as $0,1,2,3$ and 4 depending on the item's applicability to their organizational role (Likert scale). The scale measures ten role stressors (Table-01).ORS scores were classified into four categories Low-stress group (0-50), Low Medium stress group (51-100),HighMedium stress group (101-150), and the Very High-stress group (151-200). ${ }^{9}$ Further, norms for role stressors are also reported by the Pareek et.al., ${ }^{15}$ based on the mean, median and quartile deviations.In the present study, thetool was used in its original version without translation. Ethical Clearance was obtained from ethical review committee of Faculty of Medicine, Peradeniya and informed consent were obtained from the participants. In the statistical analysis, all descriptive statistics are presented as mean and standard deviations for continuous variables and as relative frequencies and percentages for categorical variables. Comparisons between means were done by using independent sample t-test and one-way ANOVA. Data were analyzed by using SPSS software.

\section{Results}

The study includes 76 respondents (out of 138 doctors) from the different wards and units at THP. The majority were male ( $n-41,53.9 \%)$ and married ( $n$ $59,77.6 \%$ ). Mean age was 36.51 (SD-6.98) years with working experience of 7.94 (SD-6.09) years on average. Further information on socio-demographic characteristics was given in table 02 .

Mean ORS score of the study group was 65.5 (SD32.04). The majority(n-39, 51.3\%) of the doctors were having low-medium role stress (ORS score 51$100)$ and $35.5 \%$ ( $n-27)$ had low role stress (ORS score $0-50)$. However, $11.8 \%(n-9)$ and $1.3 \%(n-1)$ had high medium role stress (ORS score 101-150) and very high role stress level (ORS score 151-200).
Table 2 - Socio-demographic profile of participants

\begin{tabular}{|c|c|c|c|}
\hline & & Count & $\%$ \\
\hline \multirow{3}{*}{ Age (years) } & $<=30$ & 18 & $23.7 \%$ \\
\hline & $31-40$ & 35 & $46.1 \%$ \\
\hline & $>40$ & 23 & $30.3 \%$ \\
\hline \multirow{2}{*}{ Sex } & Male & 41 & $53.9 \%$ \\
\hline & Female & 35 & $46.1 \%$ \\
\hline \multirow{4}{*}{$\begin{array}{l}\text { Experience } \\
\text { (years) }\end{array}$} & $0-5$ & 34 & $44.7 \%$ \\
\hline & $5-10$ & 21 & $27.6 \%$ \\
\hline & $10-15$ & 10 & $13.2 \%$ \\
\hline & $>15$ & 11 & $14.5 \%$ \\
\hline \multirow{3}{*}{ Designation } & IMO & $911.8 \%$ & \\
\hline & MO & 62 & $81.6 \%$ \\
\hline & $P G$ & $56.6 \%$ & \\
\hline \multirow{2}{*}{ Marital status } & Single & 17 & $22.4 \%$ \\
\hline & Married & 59 & $77.6 \%$ \\
\hline \multicolumn{4}{|c|}{$\begin{array}{l}\text { IMO - Intern Medical Officer, MO- Medical Officer, } \\
\text { PG-Post Graduate trainee }\end{array}$} \\
\hline
\end{tabular}

IMO - Intern Medical Officer, MO- Medical Officer, PG-Post Graduate trainee

As shown in Table 03 even though it is not statistically significant male doctors are having higher role stress than female doctors. On the other hand, thestatistically significant relationship was found between marital status, age, years of experience and management level.

Table 04 shows rankings of role stressors. Inter-Role Distance (IRD), Role Stagnation (RS), Role Overload (RO) and Personal Inadequacy (PI) stressors were rated as top four with mean scores above 7 and Role Ambiguity (RA) was rated as the least important stress factor by the doctors in the present study.

\section{Discussion}

The mean score in this study shows that role stress was experienced, comparatively in higher amounts by medical officers in this study, compared to the reported norms.15Mean scores of most of the stressors have found to be on higher side except RE and RI.Inter-Role-Distance, RS, RO, and PI reported as the major role related problems among thestudy group. A studydone in India9also found IRD as the most problematic role stressor among government doctors, whereas two other studies ${ }^{10-12}$ reported RO as the highest rated role stressor.

Inter-Role Distance (IRD) is a conflict between multiple roles played by a worker (eg - doctor, head of the family, member of a society). When one role is 
Table 3 -Factors associated with Organizational Role Stress (ORS)

\begin{tabular}{|c|c|c|c|c|c|c|}
\hline \multirow{2}{*}{\multicolumn{2}{|c|}{ Variables }} & \multirow{3}{*}{$\begin{array}{l}n \\
41\end{array}$} & \multicolumn{2}{|c|}{ ORS score } & \multirow{3}{*}{$\begin{array}{l}\mathrm{t} / \mathrm{f} \\
\text { ratio } \\
0.46\end{array}$} & \multirow{3}{*}{$\begin{array}{l}\text { sig. } \\
0.65\end{array}$} \\
\hline & & & Mean & SD & & \\
\hline \multirow{2}{*}{ Sex } & Male & & 67.07 & 28.91 & & \\
\hline & Female & 35 & 63.66 & 35.69 & & \\
\hline \multirow{2}{*}{ Marital status } & Unmarried & 17 & 80.41 & 34.91 & 2.23 & $0.03 *$ \\
\hline & Married & 59 & 61.20 & 30.12 & & \\
\hline \multirow{3}{*}{ AGE (years) } & $<=30$ & 18 & 73.56 & 39.04 & 4.72 & $0.01^{*}$ \\
\hline & $31-40$ & 35 & 72.09 & 28.14 & & \\
\hline & $>40$ & 23 & 49.17 & 26.38 & & \\
\hline \multirow{2}{*}{ Experience (years) } & $<10$ & 55 & 72.22 & 31.49 & 3.13 & $0.003^{*}$ \\
\hline & $>10$ & 21 & 47.90 & 26.86 & & \\
\hline \multirow{3}{*}{ Designation } & IMO & 9 & 98.11 & 36.05 & 7.16 & $0.01 *$ \\
\hline & MO & 62 & 59.66 & 29.54 & & \\
\hline & $P G$ & 5 & 79.20 & 13.35 & & \\
\hline \multicolumn{7}{|c|}{$*$ p value $<0.05$} \\
\hline \multicolumn{7}{|c|}{ ORS - Organizational Role Stress } \\
\hline
\end{tabular}

Table 4 - Rankings of Role Stressors

\begin{tabular}{|llllll|}
\hline \multicolumn{1}{|c}{ Role Stressors } & Mean & SD & Median & Rank & $\begin{array}{c}\text { Norm mean } \\
\text { score(Median) }\end{array}$ \\
\hline $\begin{array}{l}\text { Inter-Role } \\
\text { Distance (IRD) }\end{array}$ & 8.39 & 4.90 & 8 & 1 & $5(5)$ \\
\hline $\begin{array}{l}\text { Role Stagnation } \\
\text { (RS) }\end{array}$ & 7.39 & 4.66 & 6.5 & 2 & $5(5)$ \\
\hline $\begin{array}{l}\text { Role Expectation } \\
\text { Conflict (REC) }\end{array}$ & 6.03 & 4.40 & 5 & 8 & $4.3(4)$ \\
\hline $\begin{array}{l}\text { Role Erosion (RE) } \\
\text { Role Overload (RO) }\end{array}$ & 7.20 & 4.18 & 6 & 7 & $9.3(9)$ \\
\hline $\begin{array}{l}\text { Role Isolation (RI) } \\
\text { Rer }\end{array}$ & 5.78 & 3.70 & 5 & 9 & $6(6)$ \\
\hline $\begin{array}{l}\text { Personal } \\
\text { Inadequacy (PI) }\end{array}$ & 7.05 & 4.26 & 7 & 3 & $4.6(4)$ \\
\hline $\begin{array}{l}\text { Self-Role (SRD) } \\
\text { Distance (SRDity (RA) }\end{array}$ & 6.30 & 4.24 & 6 & 6 & $5.6(5)$ \\
\hline Role Ambiguity & 3.52 & 4.5 & 10 & $3.6(3)$ \\
\hline $\begin{array}{l}\text { Resource } \\
\text { Inadequacy (RIN) }\end{array}$ & 6.59 & 4.05 & 6 & 5 & $5(5)$ \\
\hline \begin{tabular}{l} 
TOTAL \\
\hline
\end{tabular} & 65.50 & 32.04 & 63.5 & & $51(45)$ \\
\hline
\end{tabular}


demanding more of his time and attention, it will cost the others, giving rise to the IRD. IRD is the highest rated stressor among doctors in this study.

Role Stagnation (RS) got the second highest rating by the doctors at THP. This results in the perception that there is no opportunity for learning and development in the role. In other words "feeling of being stuck in the same role." ${ }^{\prime 9}$ Timely promotions and provision of postgraduate study opportunities could address the issue of role strangulation.

Third role stressor identified among doctors in this study was Personal Inadequacy (PI). This can occur "when a role occupant feel that he does not have enough knowledge, skills or training to undertake a role effectively, or he has not had time to prepare for the assigned role, he may experience role stress". 10 This may be because $44.7 \%$ of the doctors in this study have 5 or less than 5 years' experience.Personal inadequacy could be diminished with appropriate training and development of skills required for doctors based on their specific role. Continuous professional development programs, which are tailor-made for the new challenges appearing in the health sector is aprerequisite to address these issues.

Role Overload (RO) rated fourth, describes the situations in which workers feel that there are too many responsibilities and activities expected of them. Doctors in this study also suffered from role overload.

Role Ambiguity (RA) is found to be the least problematic role stressor among the study group. RA sets in when there is alack of clarity about theexpectation of others from the role or lack of feedback on how performance is regarded by others. Generally, Role ambiguity is experienced by persons occupying roles that are newly created in organizations, roles that are undergoing change, which is not an issue for doctors. This finding is compatible with the findings of several role stress studies conducted among doctors. $9,10,12$.

Marital status, age, experience and management level are found to be having astatistically significant relationship with the overall ORS score among the doctors in the present studyas reported in a study done among Indian doctors. ${ }^{12}$ Even though sex is not showna statistically significant relationship with the ORS score in the present study, higher mean ORS scores were reported by the male doctors compared to female doctors as in several other studies. ${ }^{9,10}$

Thereluctance of doctors to fill the questionnaire was felt the major difficulty in carrying out this study and out of 138 doctors working in the THP, only 76 doctors responded, giving rise to a high level of non-re- sponse rate. Previous studies of this kind also reported having this problem. ${ }^{9}$ Therefore the findings of this study may be subjected to the different types of biases which comes into play with high non-response rate and small sample size. Nevertheless, our study contributes to the existing literature by describing the role stressors of Sri Lankan group of doctors and directing towards more detailed analysis based on a study with a larger sample.

\section{Conclusion}

Findings of this study revealed that doctors working at THP are suffering from medium to high levels of ORS and IRD, RS, RO, and PI reported as the major role related problems among thestudy group. Role Ambiguity (RA) is found to be the least problematic role stressor among doctors. The findings of this study demand the attention of administrators and policymakers, to provide an attractive working climate in order to decrease the side effects and consequences of role stress and increase the productivity of the doctors. Public health implications

\section{Author Declarations}

Competing interests: The authors declare that they have no competing interests.

Acknowledgements: We are grateful to our study participants.

Author contributions: DG was the principal investigator of the study. PH, SM, RA and SW were involved in the design, acquisition of data, analysis and interpretation of data. DG was involved in drafting the manuscript. DA, SM, RA,SW and $\mathrm{PH}$ revised it critically for important intellectual content and gave approval for the final the version.

\section{References}

1. Nirmala KV, Babu MS. Comparative Study of Occupational Stress among Health Care Professionals in Government and Corporate Hospitals. International Journal of Engineering Management Research. 2015;5(3):242-247.

2. Selye, H. (1956). The stress of life. McGraw-Hill.

3. Moore KA, Cooper CL. Stress in mental health professionals: A theoretical overview. International Journal of Social Psychiatry. 1996;42(2):82-89.

4. Kahn RL, Wolfe DM, Quinn RP, Snoek JD, Rosenthal RA. Occupational stress: Studies in role conflict and ambiguity. New York: Wiley; 1964. 
5. Pareek U. Organisational Role Stress (Manual, Scale, and Answer Sheet). In: Navin Publications, Ahmedabad, India; 1983.

6. Wijeratne M. Prevelance of psychological distress, factors associated with work stress and coping strategies adapted by Information Technology Professionals, Post Graduate of Medicine (PGIM), University of Colombo, Sri Lanka; 2006.

7. Ellawela Y, Fonseka P. Psychological distress, associated factors and coping strategies among female student nurses in the Nurses' Training School Galle. Journal of the College of Community Physicians of Sri Lanka. 2011;16(1):23-29.

8. Antoniou A-S, Cooper CL, Davidson MJ. Levels of job dissatisfaction and work-related stressors experienced by medical doctors in Greek hospitals. Journal of Compassionate Health Care. 2016;3(1):4.

9. Baba I. Workplace stress among doctors in government hospitals: an empirical study. International Journal of Multidisciplinary research. 2012;2(5):208-220.

10. Dasgupta H, Kumar S. Role stress among doctors working in a government hospital in Shimla. European Journal of Social Sciences. 2009;9(3):356-370.

11. Firth-Cozens J. Doctors, their wellbeing, and their stress. British Medical Journal. 2003;326(7391):670-671.

12. Cardoso PA, Fernandes CFV. Marital Status, Management Level and Social Support Differential in Organizational Role Stress among Doctors. European Journal of Social Sciences. 2011;20(3):452-458.

13. Vasudevan V. Do Organizational Stress Really Matters in Career Satisfaction? In: Hamburg : Diplomica Verlag; 2015.

14. Yasmeen H, Supriya M. Organizational role stress: confirmatory factor analysis approach. Asia Pacific Business Review. 2008;4(2):29-33.

15. Pareek UN. Training instruments for human resource development. Tata McGraw-Hill; 1997. 